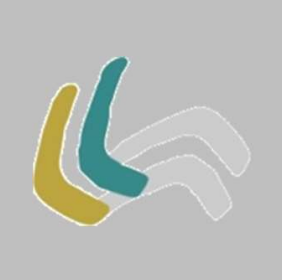

\title{
ANOTAÇÕES SOBRE O NEOMEDIEVALISMO EM CANTIGAS DE AMARES, DE LEDA MARIA MARTINS
}

NOTES ON NEOMEDIEVALISM IN CANTIGAS DE AMARES, BY LEDA MARIA MARTINS

\author{
Henrique Marques Samyn ${ }^{1}$ \\ Universidade do Estado do Rio de Janeiro
}

Resumo: O presente artigo tenciona apresentar algumas considerações acerca de uma pesquisa em construção, cujo objeto central são composições poéticas presentes no livro Cantigas de amares, da escritora brasileira Leda Maria Martins. O artigo resgata as condições de emergência da investigação, no âmbito da trajetória acadêmica do pesquisador proponente; apresenta alguns apontamentos sobre o conceito de neomedievalismo na poesia brasileira, conforme proposto por Maria do Amparo Tavares Maleval; e expõe, em linhas gerais, a questão central da investigação proposta, ilustrando-a com alguns apontamentos iniciais sobre o poema intitulado "Cantiga 1".

Palavras-Chave: Neomedievalismo; Poesia brasileira; Poesia de autoria negra.

1 Endereço eletrônico: marquessamyn@gmail.com. 
Abstract: The article aims to present some remarks related to a research about some poetic compositions of Cantigas de amares, book published by Brazilian writer Leda Maria Martins. The article describes the origins of the research, within the academic trajectory of the proposing researcher; presents some notes on the concept of neomedievalism in Brazilian poetry, as defined by Maria do Amparo Tavares Maleval; and addresses the central question of the research, also presenting some initial notes on the poem entitled "Cantiga 1".

Keywords: Neomedievalism; Brazilian poetry; Brazilian Black poetry.

\section{À MANEIRA DE INTRODUÇÃO}

Meu propósito, neste ensaio, é dissertar brevemente sobre uma pesquisa em construção, esboçada para desenvolvimento ao longo dos próximos anos. Trata-se, com efeito, de encetar a tarefa de explorar um território novo, o que sempre constitui um empreendimento tão estimulante quanto desafiador; e que, por outro lado, oferece condições propícias para uma ponderação acerca dos caminhos percorridos até as fronteiras da região perante a qual agora me encontro.

Desse modo, a fim de delinear o itinerário que trilharei nas próximas páginas, proponho-me partir de duas questões elementares: primeiro, refletir acerca das sendas que me trouxeram a este lugar, ou seja, sobre as condições de emergência dessa nova investigação; segundo, apresentar alguns apontamentos iniciais - ainda que, inevitavelmente, em um sentido conjectural - em torno do meu novo objeto de pesquisa.

Como anuncia o título do texto - "Anotações sobre o neomedievalismo em Cantigas de amares, de Leda Maria Martins" -, minha proposta de pesquisa tenciona construir uma interpretação sobre algumas composições de uma escritora brasileira nas quais o influxo da poética trovadoresca é evidente. Tratase, portanto, de uma pesquisa que articulará a literatura medieval galega com a literatura brasileira de autoria negra, a partir do conceito de neomedievalismo; e 
que se inscreve em um amplo conjunto de investigações que venho realizando nos últimos anos, nesses dois campos.

\section{DAS SENDAS PRIMEIRAS}

Rastrear exaustivamente as origens dessa pesquisa demandaria, em primeiro lugar, retornar até o ano de 2004 - ano em que, a convite da professora Maria do Amparo Tavares Maleval, ingressei como pesquisador voluntário no Programa de Estudos Galegos da Universidade do Estado do Rio de Janeiro (Proeg - UERJ). Assim teria início uma colaboração que se prolonga até os tempos atuais, o que pode ser atestado por minha participação regular nas Jornadas de Estudos Galegos, realizadas anualmente na UERJ, além de palestras e cursos realizados no âmbito do referido núcleo. Minha aproximação com Maleval - com quem desenvolvi atividades em parceria até poucos anos antes de seu falecimento, no início de 2021, vitimada pelo descaso com que as autoridades governamentais brasileiras vêm tratando a pandemia de covid-19 - deu-se em decorrência do meu encontro casual com uma de suas mais instigantes publicações: o livro Poesia medieval no Brasil (2002), que tive a oportunidade de conhecer apenas dois anos após seu lançamento.

No estudo introdutório ao referido volume, Maleval apresenta algumas considerações acerca da relação entre a poesia brasileira e a tradição medieval peninsular. Após dissertar sobre o neotrovadorismo galego, ressaltando suas especificidades -

o Neotrovadorismo galego inscreve-se nos movimentos de afirmação das identidades regionais reprimidas em maior ou menor grau desde o advento das Nações, observados na atualidade, a par dos avanços tecnológicos que tornam cada vez mais possível a internacionalização da cultura. Constituem verdadeiros "bolsões de resistência" à descaracterização político-cultural, fragmentando o que parecia tendente a desaparecer na globalização aludida, retrocedendo às origens medievais, quando se forjavam as línguas do 
Ocidente, fatores por excelência de identidade de cada povo. (MALEVAL, 2002, p. 24)

- observa a autora que "muitos dos primeiros 'neomedievalistas' brasileiros são contemporâneos ou participantes do movimento modernista" (MALEVAL, 2002, p. 27); ou seja, inscrevem-se em um conjunto de manifestações literárias cujos postulados básicos são "a luta pela emancipação da nossa literatura, da nossa língua, em relação aos modelos portugueses e o combate aos extenuados valores europocentristas" (MALEVAL, 2002, p. 28). Em decorrência disso, Maleval opta pela expressão "neomedievalismo brasileiro", definido como um conjunto de práticas heterogêneas de poetas que raramente procuravam retomar as estruturas medievas; em vez disso, construíam composições que, embora apresentassem em seus títulos elementos que remetiam aos gêneros medievais, "apenas se restringiram a manter-lhes alguns vocábulos específicos, outras vezes a parafrasear um texto arcaico, tomá-lo como mote a ser glosado ou com ele dialogar literalmente, trazendo-o para o interior do novo poema" (MALEVAL, 2002, p. 37).

Apesar de meu interesse por Poesia medieval no Brasil, tanto por razões pessoais quando por motivos acadêmicos, não percorri mais profundamente essas sendas naquele momento. Limitei-me a apresentar e a publicar um trabalho que abordava um poema neomedievalista de Manuel Bandeira (SAMYN, 2005); todavia, o doutorado me levaria para outros caminhos - designadamente, a pesquisa sobre as pastorelas galego-portuguesas, occitânicas e médio-latinas da qual resultou uma tese recentemente publicada em livro (SAMYN, 2019). Apenas cerca de quinze anos depois eu retornaria à obra de Maleval, justamente em função dos interesses que agora me movem. 


\section{AO ENCONTRO DE LEDA}

Dedicando-me a tarefas de docência e pesquisa na Universidade do Estado do Rio de Janeiro desde 2012, ano em que ingressei na referida instituição como professor concursado, prontamente direcionei minhas atividades para os campos de estudo que, já desde aquela época, mais me pareciam instigantes e relevantes: as investigações em torno da literatura desde perspectivas teóricas que enfatizam questões relacionadas a gênero e raça. Presentes nas minhas produções acadêmicas, bem como nas disciplinas e cursos que venho ministrando - na UERJ e em outras instituições - ao longo do tempo, essas pesquisas não me afastaram da literatura galega; pelo contrário: elas estavam entre as motivações fulcrais subjacentes a trabalhos que desenvolvi, entre 2014 e 2020, sobre as soldadeiras medievais (SAMYN, 2014; SAMYN, 2018; SAMYN, 2019; SAMYN, 2020a; SAMYN, 2020b; SAMYN, 2020c) $)^{2}$.

Entretanto, a conclusão da referida pesquisa ensejou a necessidade de constituir um novo objeto de investigação, para o período que se inicia no ano corrente - ou seja: 2021. Nesse sentido, optei por dedicar-me ao estudo de uma autora que só recentemente descobri - e que, a meu ver, não tem recebido uma atenção crítica compatível com a relevância de sua obra. Refiro-me a Leda Maria Martins.

Deparei-me com Leda no âmbito de minhas investigações acerca de intelectuais negras no Brasil. Doutora em Estudos Literários, Leda atuou como docente e pesquisadora em importantes universidades brasileiras - Universidade Federal de Ouro Preto (UFOP) e Universidade Federal de Minas Gerais (UFMG); assinou obras fulcrais sobre a dramaturgia brasileira - O moderno teatro de Qorpo-

\footnotetext{
2 Limito-me a elencar, aqui, artigos e capítulos de livros publicados no período referido; por conseguinte, excluo conferências, palestras, cursos de extensão e demais atividades ministradas em diversas universidades brasileiras. Também não listo publicações que, no momento em que redijo este artigo, estão "no prelo".
} 
Santo (MARTINS, 1991) e A cena em sombras (MARTINS, 1995); e publicou Afrografias da memória, estudo seminal sobre os Reinos Negros e os Congados de Minas Gerais (MARTINS, 1997). Não obstante, enquanto se dedicava à construção de sua importante trajetória acadêmica, Leda Maria Martins também se dedicou à criação literária, de que resultaram dois volumes de poesia: Cantigas de amares (MARTINS, 1983) e Os dias anônimos (MARTINS, 1999). A publicação desses volumes ensejou sua inclusão em uma das mais relevantes compilações da literatura brasileira de autoria negra até hoje publicadas: a antologia Literatura e afrodescendência no Brasil, organizada por Eduardo de Assis Duarte (2011).

Havendo me deparado com a produção lírica de Leda Maria Martins, um dos aspectos que mais me chamou a atenção foi, precisamente, o componente "neomedievalista" de sua obra, já sugerido pelo título de seu primeiro livro: Cantigas de amares, publicado em 1983, em edição autoral, com ilustrações de Regina Coeli Rennó. Com efeito, constam dessa obra diversas cantigas que explicitamente dialogam com a poesia trovadoresca - e que, até onde fui capaz de averiguar, não foram objeto de quaisquer análises mais aprofundadas, em que pesem os sucintos comentários de Maria do Carmo Figueiredo, autora do verbete dedicado à escritora na antologia supracitada (2011, p. 168-169). Essa produção lírica de Leda Maria Martins, de fato, não consta da antologia publicada por Maria do Amparo Tavares Maleval em Poesia medieval no Brasil; na verdade, não há quaisquer menções à autora no referido volume - o que não constitui propriamente um problema, visto que Maleval reconheceu, na própria obra, os limites de seu trabalho, determinados por fatores diversos, desde as dificuldades no que diz respeito à obtenção dos direitos para a publicação até a escassez de experiências neomedievalistas em certos autores (MALEVAL, 2002, p. 37). No caso específico de Leda Maria Martins, suponho que a ausência não tenha sido determinada por esses fatores, mas pela dificuldade de acesso ao material - visto que, como anteriormente mencionado, Cantigas de amares foi publicado apenas 
em edição autoral, em uma época na qual havia ainda mais empecilhos à circulação de livros no Brasil. Vale observar que algumas das composições presentes em Cantigas de amares reaparecem (com alterações eventuais) em Os dias anônimos, segundo livro de poemas de Leda, já publicado com a chancela de uma casa editorial - o que, ao menos idealmente, favoreceria a veiculação da obra; contudo, desse conjunto não fazem parte as "cantigas".

\section{DAS LEITURAS POSSÍVEIS}

A partir dos elementos anteriormente expostos, assim formulo a questão que me interessa investigar - no âmbito de uma pesquisa mais ampla, em construção, acerca da experiência como fundamento na literatura luso-brasileira de autoria negra, à luz dos estudos de gênero e raça: como é possível entender a presença de aspectos neomedievalistas na produção lírica de Leda Maria Martins?

Em um estágio inicial, o corpus da pesquisa reunirá um conjunto de poemas constantes de Cantigas de amares nos quais o influxo trovadoresco se faz mais visível: as "Cantigas", numeradas de 1 a 4 ; e, eventualmente, outros poemas nos quais a incidência daqueles elementos pode ser percebida, ainda que tacitamente (caso de "Reflexos", “Teares" e “O desejado", por exemplo). Com o mero fim de sugerir possíveis encaminhamentos para a investigação proposta, aqui apresento algumas considerações iniciais, reconhecidamente incipientes, decorrentes de uma primeira leitura da "Cantiga 1", com especial atenção para os aspectos mais relevantes para os meus propósitos.

Segundo poema de Cantigas de amares, “Cantiga 1" (MARTINS, 1983, p. 5) já se configura como uma composição neomedievalista pela expressão que abre seu verso inicial: "Ai, mia senhor" - expressão associada à denominação mais frequente nos cancioneiros peninsulares, tanto na vertente profana quanto na 
religiosa; e que, no que tange à poética trovadoresca, "ocupa um papel substancial na definição do gênero [cantiga de amor]" (CORRAL DÍAZ, 1996, p. 92; 96; tradução minha). Não obstante, apesar da adoção de uma voz lírica masculina - procedimento também característico do gênero, em que "se move a razon d'ele", para citar ipsis litteris a "Arte de Trovar" do Cancioneiro da Biblioteca Nacional de Lisboa (TAVANI, 1999, p. 41) -, quaisquer conjecturas de que o poema constitua uma tentativa de recriação rigorosa das estruturas poéticas medievais logo se revelam malogradas, uma vez que já o terceiro verso da estrofe inicial tem ressonâncias eróticas estranhas ao gênero:
Ai, mia senhor, a solitude é
$\mathrm{Ai}$, minha senhor, a solitude vence
E quero tuas mãos não as minhas na pele
E quero teus olhos não os meus nos pêlos
(MARTINS, 1983, p. 5)

Para além disso, na poética medieval galego-portuguesa, a cantiga de amor se caracterizava pelo escasso descritivismo - visto que, nessas composições, "a amada é uma dama abstrata, pura forma idealizada, intangível" (ARIAS FREIXEDO, 2003, p. 79; tradução minha). Desse modo, as menções a partes do corpo feminino (as mãos e os olhos, na primeira estância; as mãos e os dedos, na segunda estrofe; o ventre e a saliva, na quarta e última estância) assomam como elementos que demarcam a clivagem entre as cantigas medievais e a composição contemporânea. Note-se, a esse respeito, que mesmo nos raros casos de cantigas medievais nas quais ocorre uma descrição mais concreta do corpo da amada, esta é bastante escassa - vejam-se, por exemplo, as cantigas "Amigos, non poss'eu negar", de João Garcia de Guilhade (A 229, B 419, V 30); e “Senhor do corpo delgado", de Pero da Ponte (A 292, B 983, V 570)³.

3 Limito-me a citar aqui o par de exemplos evocado por Xosé Bieito Arias Freixedo (2003). 
Com efeito, na própria configuração do poema de Leda Maria Martins, evidenciadora de seu refinado manejo dos processos de criação literária, transparece um progressivo afastamento do registro mais próximo da dicção medieval, nítido na estrofe inicial - vejam-se não apenas a já referida expressão "Ai, mia senhor", que abre os primeiros versos, mas também a presença de um erotismo que, embora anômalo, ocorria de modo mais suavizado -, em direção a uma modulação mais contemporânea - uma vez que, nas estrofes finais, a manifestação do desejo ocorre de modo mais intenso e explícito, a tal ponto que a inserção daquela expressão assume um aspecto quase paródico. Isso pode ser percebido na estrofe final da cantiga, que transcrevo:

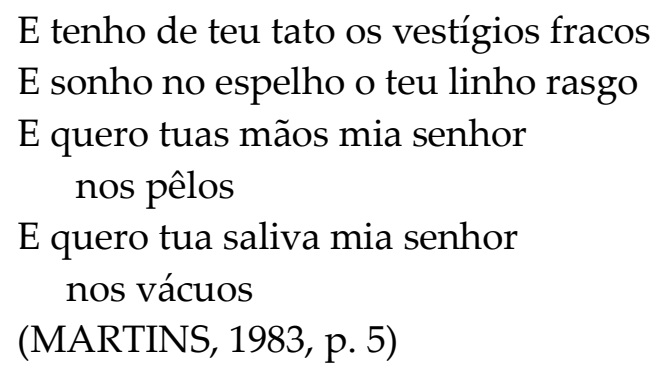

\section{CONCLUSÃO: À PROCURA DE UMA EXPERIÊNCIA}

Os brevíssimos apontamentos aqui coligidos em torno da "Cantiga 1" de Leda Maria Martins tencionam, meramente, ilustrar algumas das instigantes questões suscitadas pela produção lírica da autora. Importa não apenas aprofundar essa leitura (abordando, por exemplo, a estrutura formal da composição), como também investir em uma leitura que articule essa obra com as outras "Cantigas" presentes no volume - e que, como adequadamente observa Maria do Carmo Figueiredo (2011, p. 169), mais se aproximam das cantigas de amigo trovadorescas. Desse modo, será possível dimensionar e analisar mais adequadamente o resgate da poética galego-portuguesa na produção da escritora brasileira. 
Contudo, em consonância com as questões sobre as quais venho me debruçando ao longo dos últimos anos, interessa-me compreender as criações líricas de Leda Maria Martins como obras produzidas por uma autora que ocupa uma posição social específica - ou seja: como intelectual mulher e negra. Para além de leituras generalizantes, que tendem a negligenciar as condições concretas de produção da obra literária, interessa-me considerar de que modo essa posição particular determina o resgate dos elementos medievais; apenas isso, a meu ver, oferecerá os subsídios imprescindíveis para a efetiva compreensão de sua riqueza e singularidade.

\section{REFERÊNCIAS}

ARIAS FREIXEDO, Xosé Bieito. Antoloxía da lírica galego-portuguesa. Vigo: Ediciós Xerais de Galicia, 2003.

CORRAL DÍAZ, Esther. As mulleres nas cantigas medievais. A Coruña: Seminario de Estudos Galegos - Ediciós do Castro, 1996.

DUARTE, Eduardo de Assis (Org.). Literatura e afrodescendência no Brasil. 4v. Belo Horizonte: Editora UFMG, 2011.

FIGUEIREDO, Maria do Carmo L. Leda Maria Martins. In: DUARTE, Eduardo de Assis (Org.). Literatura e afrodescendência no Brasil. 4v. Belo Horizonte: Editora UFMG, 2011.

MALEVAL, Maria do Amparo Tavares. Poesia medieval no Brasil. Rio de Janeiro: Ágora da Ilha, 2002.

MARTINS, Leda Maria. A cena em sombras. São Paulo: Perspectiva, 1995.

MARTINS, Leda Maria. Afrografias da memória. São Paulo: Perspectiva; Belo Horizonte: Mazza Edições, 1997.

MARTINS, Leda Maria. Cantigas de amares. Belo Horizonte: s./ed., 1983.

MARTINS, Leda Maria. O moderno teatro de Qorpo-Santo. Belo Horizonte: Editora UFMG; Mariana: UFOP, 1991.

MARTINS, Leda Maria. Os dias anônimos. Rio de Janeiro: Sette Letras, 1999.

SAMYN, Henrique Marques. A morte e o mar: Mendinho e Manuel Bandeira. In: Atas da VI Semana de Estudos Medievais. Rio de Janeiro: Programa de Estudos Medievais, 2005, p. 351-357. 
SAMYN, Henrique Marques. A pastora e a alegoria: a invenção da pastorela alegórica - da lírica occitânica aos Carmina Burana e ao trovadorismo galego-português. Niterói: Editora da Universidade Federal Fluminense, 2019.

SAMYN, Henrique Marques. A soldadeira e seus clérigos: para uma leitura feminista de "Mayor Garcia ssenpr' oy[o] dizer" (B 1455/V 1065), de João Baveca. Idioma, v. 27, 2014, p. 39-48.

SAMYN, Henrique Marques. Do erotismo entre mulheres em duas cantigas trovadorescas: sobre Mari'Mateu, ir-me quer'eu daquém (B 1583, V 1115), de Afonso Anes do Cotom; e A vós, Dona Abadessa (B 1604bis, V 1137), de Fernando Esquio. In: CARDOSO, Patrícia da Silva; BUENO, Luís. (Org.). Nós e as Palavras. Cotia: Ateliê Editorial, 2018, p. 203-218.

SAMYN, Henrique Marques. Elvira Lopez, seu 'Peom' e sua 'Maeta': sobre duas cantigas satiricas de Joao Garcia de Guilhade. Texto Poético, v. 16, 2020a.

SAMYN, Henrique Marques. Feminilidades desviantes na lírica trovadoresca galegoportuguesa: acerca de três cantigas sobre soldadeiras. Signum, v. 20, 2020b, p. 22-43.

SAMYN, Henrique Marques. Sobre a "negrura" de Maria Negra: apontamentos sobre três cantigas satíricas de Pero Garcia Burgalês. Abriu: estudos de textualidade do Brasil, Galicia e Portugal. v. 9, 2020c, p. 125-142.

TAVANI, Giuseppe. Arte de trovar do Cancioneiro da Biblioteca Nacional de Lisboa. Lisboa: Edições Colibri, 1999.

Nota do editor:

Artigo submetido para avaliação em: 11 de março de 2021.

Aprovado em sistema duplo cego em: 12 de agosto de 2021. 